\title{
Intrasexual Competition as a Predictor of Women's Judgments of Revenge Pornography Offending
}

\section{Dean Fido' (iD, Craig A. Harper' ${ }^{\text {ID }}$, Mia A. Davis², Dominic Petronzi', and Sophie Worrall'}

\begin{abstract}
Recent legislative developments have led to a marked increase in the empirical investigation of motivations and judgments of so-called acts of "revenge pornography" offending. In two independently sampled studies, we used moderation analyses to investigate whether higher levels of intrasexual competition predicted more lenient judgments of revenge pornography offenses as a function of sex (Study I, $N=24 I$ ), and whether such relationships would be further moderated by physical attractiveness (Study 2, N = 402). Potential covariates of callous-unemotional traits, empathy, and victimization history were controlled for. Opposing our hypotheses, we consistently observed a trend for higher levels of intrasexual competition being associated with more lenient judgments of revenge pornography offenses involving male victims by female participants. The results are discussed in terms of intrasexual competition potentially sharing variance with unobserved constructs in the wider sexological literature, and of the key relevance of these findings for future empirical investigation into judgments of nonconsensual image-based offending.
\end{abstract}

\section{Keywords}

nonconsensual image-based offending, revenge porn, intrasexual competition, empathy, callous-unemotional traits

University of Derby, UK

${ }^{2}$ Nottingham Trent University, UK

Corresponding Author:

Dean Fido, Enterprise Centre, University of Derby, Bridge Street, Derby DEI 3LD, UK.

Email: d.fido@derby.ac.uk. 


\section{Introduction}

Recent legislative developments in the Western world, as well as high-profile celebrity scandals, have led to revenge pornography emerging as a topic of social and empirical inquiry. Revenge pornography falls under the umbrella term of "non-consensual pornography" (Patella-Rey, 2018) and involves an individual "leaking" private sexual images of another. This act is usually a result of a relationship breakdown (Dawkins, 2015) and is often used to damage an ex partner's social reputation (Henry \& Powell, 2014). Victims of revenge pornography not only face professional consequences, such as having their contracts terminated on the grounds of damaging an organization's reputation (Citron \& Franks, 2014), but they also suffer pervasive symptoms of depression, anxiety, and ongoing difficulties with regard to trusting others and their general self-image (Bates, 2017). Such consequences, in some cases, have resulted in elevated rates of suicide attempts and completions (Stroud, 2014). As such, informing policy through constructing a greater understanding of this form of sexual offending behavior is a priority.

Although the severity of punishment varies (i.e., from a fine to imprisonment), the nonconsensual sharing of sexually explicit images is a punishable criminal offense across most of the United States (38 states, plus Washington, D.C.), Australia, Canada, and Europe. Since the criminalization of revenge pornography offending in the Courts and Criminal Justice Act 2015 (United Kingdom), more than 1,000 cases were reported by police forces in England and Wales in the latter half of 2015, with $61 \%$ of these cases resulting in no action being taken against the perpetrator (Sherlock, 2016). A noticeable gap in the emerging revenge pornography literature is how public and judicial judgments of revenge pornography offenses may be influenced by psychosocial factors. Our aim in this article is to understand how one such factor, intrasexual competition, influences judgments of revenge pornography, and whether or not this association is further moderated by variation in perceived attractiveness of the victim.

\section{Understanding Potential Drivers of Revenge Pornography Judgments}

The prevalence of revenge pornography perpetration and victimization is largely unclear. The main reason for this is summarized in Walker and Sleath's (2017) systematic review in which they highlight a lack of consistency in terms of "populations examined, questions/measurements used, definitions employed, time periods over which the behaviors were measured, and how prevalence was calculated" (p. 21). However, best estimates suggest that as a function of sex, and contrary to popular and academic commentaries on the issue (see McGlynn et al., 2017), males are more likely than females to be both victims and perpetrators of revenge pornography offenses (Walker and Sleath, 2017).

Consistent with other work in areas of sexual crime, judgments of revenge pornography may be rooted in attributions made about victims, their alleged role in their own victimization, and the culpability of individual offenders (Bothamley \& Tully, 2018; Henry \& Powell, 2016; Niemi \& Young, 2016). Applied to the revenge pornography 
context more specifically, recent survey-based research conducted in the United States has found high levels of support for the criminalization of the nonconsensual sharing of sexual images - particularly among female respondents. However, levels of support dropped when it was revealed that a victim in a specific case produced the images themselves (Lageson et al., 2018). Given that most cases of revenge pornography are a result of a betrayal of trust with what was at first a consensual sending of a private photo taken by the victim (Citron \& Franks, 2014), it seems that victim blaming may play a key role in judgments of the harm caused by revenge pornography offending, and further of the criminal nature of the behavior itself.

Aside from the actual act of having a private sexual image shared, Bloom (2014) details a second level of abuse for the victims of revenge pornography offenses through "commentators who hold them solely responsible for their misfortune" (p. 250). Victim blaming in this scenario stems from the agency that the victims are perceived to have had in the taking of sexual images, with many choosing to send these to current or previous sexual partners. Fay (2018) argues that there is a general apathy toward victims, and that blaming them for sending the pictures in the first place is just "a modern twist on the antiquated notion that a rape victim 'asked for it' by wearing promiscuous clothing" (p. 1844). Relatedly, Hadwin (2017) found that U.S. participants with less knowledge and exposure to information about revenge pornography were more likely to show instances of victim blaming. This emphasizes the need for media coverage that includes information about the realities of revenge pornography victimization and its impact, rather than popular articles (e.g., "23 Reasons Why You Should Never, Ever Take a Nude Pic Again"; Fern, 2014) that perpetuate the idea that victims are to blame for taking and sending images in the first instance.

Recent research into public perceptions of revenge pornography in the United Kingdom found sex differences in victim blaming, with men being significantly more likely to do this than women (Bothamley \& Tully, 2018). This is consistent with victim blaming in relation to a range of sexual offenses (McCaul et al., 1990). However, contradictory data are reported in the unpublished work of Davies (2017), which finds that in the context of a revenge pornography offense, females had a greater tendency to blame the victim than did males. This suggests that other factors may influence the effect of sex on judgments of such offenses. We outline one potential moderator of this association below, before highlighting two potential covariates that might also play a part.

Intrasexual competition. Intrasexual competition is an evolutionary concept related to competition with sexual rivals (Darwin, 1871). This process is primarily motivated by a desire to both obtain and retain mates, and involves competing for resources such as status, popularity, and money to help achieve that end (Arnocky \& Vaillancourt, 2017). With acts of revenge pornography influencing the mate value of a victim, albeit more negatively for women than for men (Buss et al., 2017), the effects of sex on judgments of this form of offending behavior may be predicted by increased levels of intrasexual competition when the victim is of the same sex as the person providing their judgments of an offense. Our consideration of an evolutionary construct in this area is not 
at odds with other theorizing in the area of sexual violence. For example, others have formulated evolutionary explanations of sexual crime perpetration (Lalumière et al., 2005; Thornhill \& Palmer, 2000). However, we are not aware of prior work that embeds an evolutionary explanation for judgments of sexual crimes.

Fisher and Cox (2011) reported four mating strategies related to intrasexual competition: (a) self-promotion, (b) competitor derogation, (c) competitor manipulation, and (d) mate manipulation. Committing, or endorsing, acts of revenge pornography may liken to competitor derogation or manipulation (through the notion of so-called "slut shaming"; Ringrose \& Renold, 2012), with this form of intrasexual competition manifesting in attempts to compete for mates using physical cues related to fertility, health, and attractiveness (Fisher and Cox, 2011), aspects that can benefit prospective offspring. For example, because of the perceived value males place on the physical attractiveness of their female mates, intrasexual competition may facilitate aggression against another over aspects related to physical appearance (Arnocky \& Vaillancourt, 2017). Men may also use indirect means to reduce the potential mate value of other men. Knapen et al. (2018) found that when paired with a taller male counterpart (height being a physically attractive trait valued by females in a male mate), shorter men would manipulate the distribution of resources to favor themselves. Furthermore, there is evidence to suggest that derogating a potential rival on the basis of her alleged sexual promiscuity is actually heightened among women. For example, Muggleton et al. (2018) found that women (but not men) were more willing to punish sexually accessible, relative to sexually restricted, women, even at a slight financial cost to themselves. McAndrew (2017) states that gossiping is a woman's "weapon of choice" when it comes to intrasexual competition due to her preference for indirect tactics (see also Campbell, 2004; Davis et al., 2018). Furthermore, work by Reynolds et al. (2018) has demonstrated how women actively harmed, rather than advanced, the reputation of another woman who they felt either directly (through flirtation) or indirectly (just by being attractive or provocatively dressed) threatened their relationship (see also Vaillancourt, 2013; Vaillancourt \& Sharma, 2011).

Considering past research into intrasexual competition triggers and rival derogation strategies, highly competitive individuals may blame victims of a revenge pornography offense to a greater extent (or ascribe lower levels of criminality to such offenses) if they are sexually attractive (vs. unattractive). This may also lead to a lower expression of sympathy or perceptions of victim harm or distress. It is here where we might also expect to see sex differences between men and women. That is, owing to observed sex differences in the sexual selection, mate choice, and mate competition literature (see Buss \& Dedden, 1990; Puts, 2016), and the review above, we might expect such judgments as a form of intrasexual rival derogation by women expressed to a greater degree than men, when victims are physically attractive. Two potential covariates of such judgments are outlined below.

Callous-unemotional (CU) traits. CU traits comprise callous, uncaring, and unemotional facets of personality that capture thoughts and behaviors defined by an absence of 
guilt, remorse, and consequence, extending further than what is considered a simple lack of empathy. These traits are thought to map onto primary, as opposed to secondary (i.e., antisocial behavior) psychopathy-related characteristics, which manifest during adolescence, but persist into adulthood (Frick, 2004). Although not previously investigated in regard to revenge pornography specifically, CU traits (and related measures of psychopathy) have been associated with an increased propensity to commit cyber- and revenge-related crimes. For example, such traits have been associated with positive views of cyberbullying (March et al., 2017; Goodboy \& Martin, 2015; Wright et al., 2018) and an increased likelihood to disseminate private sexual text messages or seek revenge, following the infidelity of a partner (Brewer et al., 2015; Clancy et al., 2019; Rasmussen \& Boon, 2014). As such, in the absence of existing revenge pornography literature, more lenient judgments on revenge pornography offending may be predicted by increased levels of CU traits.

Empathy. Empathy, or more precisely the lack thereof, can be defined as the understanding and sharing of another's emotional experience (Decety \& Lamm, 2009). Similar to CU traits, there has been no direct investigation into the role of empathy and judgments of revenge pornography to date. Research over the past decade has, however, established a strong association between heightened empathy and less favorable judgments of, and likelihood to engage in, cyberbullying (Doane et al., 2014; Steffgen et al., 2011). Moreover, empathic concern for others, in addition to the ability to take the perspective of another, has been found to mediate the negative relationship between psychopathy and forgiveness (Giammarco \& Vernon, 2014) — the absence of which, is closely associated with the desire for revenge (Ho et al., 2002). As such, it could be hypothesized that judgments of revenge pornography offenses would be less lenient in individuals who possess greater empathy, potentially as a function of them being able to take the perspective of the victim and share their affective response to victimization.

\section{Overview of Studies}

To our knowledge, no researchers have examined whether evolutionarily rooted psychological processes predict judgments of revenge pornography offending. In this article, we present two studies to begin to fill this gap in the literature. The first used a cross-sectional design with a moderation analysis to test the hypothesis that higher levels of intrasexual competition would predict lenient judgments of a revenge pornography case when the judge and victim were of the same sex. Possible covariates of CU traits and empathy, were controlled for. Building on this initial study, we then experimentally manipulated the physical attractiveness of victims in mock police reports of revenge pornography offending. Here, we predicted that the relationship between intrasexual competition and leniency judgments would be moderated by attractiveness (i.e., this relationship would be strongest when the victim was attractive and of the same sex as the judge). 


\section{Study I}

\section{Method}

Participants. For both studies, we report how we determined our sample size, all data exclusions (if any), all manipulations, and all measures in the study. To determine our target sample size, we conducted an a priori power analysis using $\mathrm{G}^{*}$ Power (version 3.1.9.2). Assuming an anticipated medium effect size (ensuring any observed effects were of practical importance) and a standard alpha level of .05, a minimum of 129 participants would be required to have $95 \%$ power in our planned analyses. We aimed to recruit up to 250 participants to account for incidents of missing data and participant withdrawals, while allowing for generalizable results. Oversampling also retains power in regression-based designs wherein interactions are present (Baguley, 2012).

After removing cases where more than $5 \%$ of the data were missing, a total of 241 U.K. participants ( $M_{\text {age }}=36.32$ years, $S D=12.78$ years; $49.8 \%$ male) completed an online questionnaire, which was advertised through the crowdsourcing website Prolific. Although it does not overcome the more general limitations of online research (e.g., a lack of environmental control and/or participant verification), Prolific is considered a viable means of participant recruitment, with data quality comparable with that obtained through face-to-face means (Peer et al., 2017). Inclusion criteria dictated that participants had to be fluent in English, aged 18 years or over, and heterosexual. Participants provided written informed consent in accordance with approved central university research protocols and national ethical guidelines by ticking a box on both the first and last pages of our online survey. All completers were reimbursed with $£ 0.60$ for their participation.

\section{Materials}

Demographics. Participants were asked to report their age, sex, and whether they were aware of any instances in the past where they themselves had been a victim of revenge pornography.

Scale for Intrasexual Competition (SIC). The SIC comprises 12 items that measure the occurrence of intrasexual competition (e.g., "I always want to beat other [wo] men") using a 7-point scale (Buunk \& Fisher, 2009). Subject nouns differed as a function of the sex of the responder. Each item is rated using a scale anchored from not at all applicable to completely applicable (Cronbach's $\alpha=.90$ ). High scores indicated greater levels of intrasexual competition.

Judgments of Revenge Pornography (JRP). JRP were measured using the procedure outlined in Bothamley and Tully (2018). Specifically, participants were asked to read a vignette outlining the breakdown of a heterosexual relationship, which resulted in the sharing of intimate images, before answering eight items (e.g., "How much do you think [victim's name] is to blame for the incident?") using a 7-point scale. Each item is rated using a scale anchored from not at all/very unlikely to definitely/very likely. Whereas Bothamley and Tully's (2018) original vignettes framed the mode of 
image dissemination as posting images online, we instead framed the act of revenge pornography as distributing images among a friendship group. The rationale for this was to avoid potential ceiling effects of participant responses. Specifically, although both posting images online or to a friendship group are intrusive and have damaging consequences, we anticipated that group-based dissemination would be viewed with less immediate condemnation and so elicit greater variability in data. In a second deviation from the original study, we opted to average the item responses to create a composite score (Cronbach's $\alpha=.81$ ), rather than use the two originally reported subscales of victim blaming and offense severity. This approach was taken due to all items seemingly mapping onto a single factor in an exploratory analysis. Reverse scoring was used to account for this disparity, and higher scores were indicative of more lenient judgments (i.e., less harm to the victim and less of a crime). Participants were randomly split into two groups; half received a vignette where the perpetrator was male, and half received a vignette where the perpetrator was female. The names "Taylor" and "Ashley" were deliberately chosen so that they could act as either sex, as these are both unisex names in the United Kingdom. Directly following the vignette, participants were asked to write a sentence of text summarizing the vignette as an attention check. An example of the vignette used is shown below:

Taylor and his girlfriend Ashley had been dating for a while. Throughout the relationship Taylor and Ashley agreed that it would be fine for Taylor to have some private naked images of Ashley on his mobile phone for him to view personally. After dating for a while, the relationship came to an end due to Ashley being unfaithful to Taylor. Following this, Ashley discovered that Taylor had been sending the intimate photos of her to his friends. Taylor had sent the photos after his and Ashley's relationship had finished.

Inventory of Callous-Unemotional Traits (ICU). The ICU comprises 24 items that assess the occurrence and intensity of callous, uncaring, and unemotional (e.g., "I do not care who I hurt to get what I want") traits (Frick, 2004). Each item is rated on a 4-point scale anchored from not at all true to definitely true, with higher scores indicative of greater levels of CU traits. Although developed for use with adolescents, the ICU has been validated for use in adult samples (Kimonis et al., 2013). We summed item responses to create a composite score (Cronbach's $\alpha=.83$ ).

Questionnaire of Cognitive and Affective Empathy (QCAE). The QCAE comprises 31 items that measure cognitive and affective (e.g., "I am inclined to get nervous when others around me seem to be nervous") dimensions of empathy using a 4-point scale (Reniers et al., 2011). Each item is rated using a scale anchored from strongly disagree to strongly agree. We summed item responses to create a composite score (Cronbach's $\alpha=.89$ ). High scores indicated increased levels of empathy.

Procedure. Both studies were approved by institutional ethical review panels prior to data collection (Study 1: Undergraduate Research Scholarship Scheme [URSS]/18/26, Study 2: Nottingham Trent University [NTU]/2018/144). Participants initially entered their 
Table I. Descriptive Statistics for Male and Female Questionnaire Scores (Study I).

\begin{tabular}{lcccr}
\hline Variable & Total & Males & Females & \\
& $M(S D)$ & $M(S D)$ & $M(S D)$ & \multicolumn{1}{c}{$p$} \\
\hline Age & $36.32(12.78)$ & $36.59(13.80)$ & $36.06(11.74)$ & .747 \\
SIC & $2.53(1.09)$ & $2.87(1.13)$ & $2.19(0.94)$ & $<.001$ \\
Revenge Pornography Judgments & $2.77(1.15)$ & $2.96(1.14)$ & $2.57(1.13)$ & .009 \\
QCAE & $90.20(11.23)$ & $86.48(10.66)$ & $93.88(10.58)$ & $<.001$ \\
ICU & $20.50(8.39)$ & $22.94(7.97)$ & $18.07(8.11)$ & $<.001$ \\
Victimization & $1.2 \%$ & $1.7 \%$ & $0.8 \%$ & .558
\end{tabular}

Note. Victimization scored by I = yes, $2=$ no. SIC $=$ Scale of Intrasexual Competition; QCAE $=$ Questionnaire of Cognitive and Affective Empathy; ICU = Inventory of Callous-Unemotional Traits.

demographic information, such as to allow the Qualtrics survey software to prepopulate the SIC measure with the appropriate male/female labels using a "loop and merge" procedure. Following this, the SIC, JRP vignette and questions, ICU, and QCAE measures were presented in a randomized order. Randomization was conducted for each participant by the survey software to reduce the likelihood of order effects influencing the data. On average, the study took less than 10 min to complete.

Analysis plan. In instances of missing data $(N=4)$, the sample mean was calculated. Assumptions were assessed (see Supplemental Material for more information). Pearson correlations were computed between the focal predictor (intrasexual competition), the dependent variable (judgments of revenge pornography), the moderator variable (sex of the victim), and covariates (CU traits, empathy, self-reported victimization) in relation to the whole sample, as well as within each sex. We then used Model 1 of the PROCESS plugin for SPSS (version 3; Hayes, 2018) to run two moderation models (one each for male and female responders) on mean-centered data. All regression coefficients for moderation models reported in this article are unstandardized, as recommended in Hayes (2018). Confidence intervals (CIs) were not bias corrected.

\section{Results}

Sex differences. Means and standard deviations for questionnaire data are reported in Table 1. Independent $t$ tests were used to delineate sex differences within our sample. Males reported greater levels of intrasexual competition, $t(239)=5.09, p<.001, d=$ 0.65 , and CU traits, $t(239)=4.70, p<.001, d=0.61$, than females, and also reported lower levels of empathy, $t(239)=-5.40, p<.001, d=-0.70$, and more lenient judgments to the perpetrators of revenge pornography offenses, $t(239)=2.62, p=.009, d=$ 0.34 . There were no significant differences in age, $t(239)=0.32, p=.747, d=0.04$, or self-reported victimization, $t(239)=0.59, p=.558, d=0.04$, between men and women.

Correlation analyses. We computed bivariate Pearson correlations between predictor, dependent, and moderator variables, as well as covariates (see Table 2). Intrasexual 


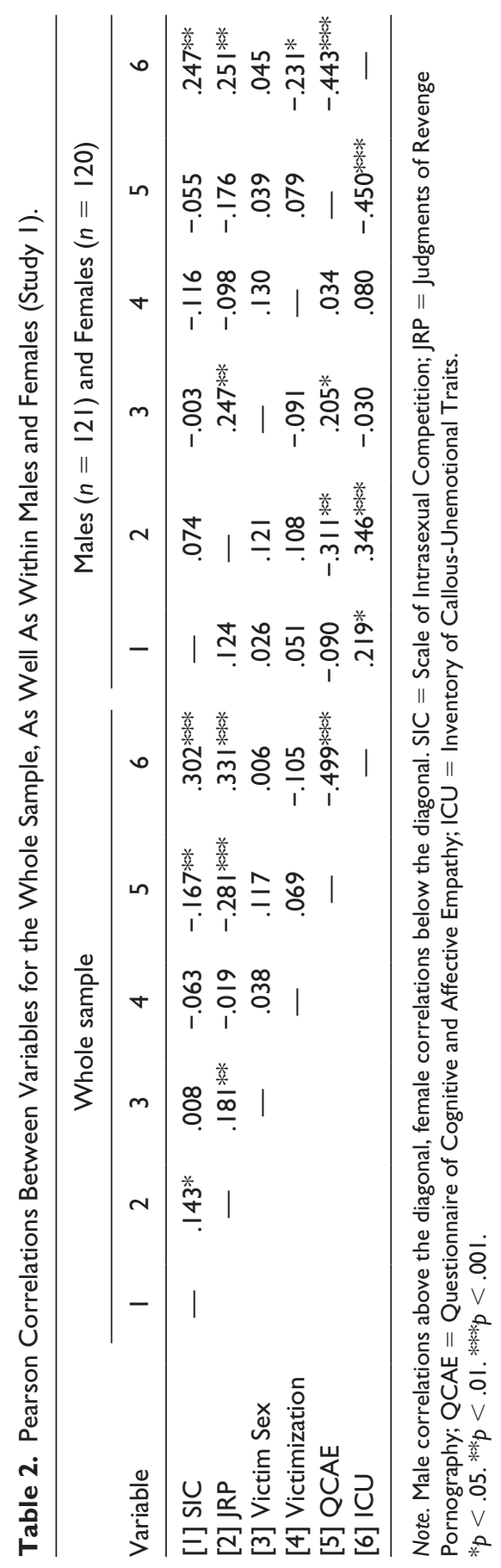


Table 3. Moderation Coefficients for Male Responders (Study I).

\begin{tabular}{lccll}
\hline Variable & $B(S E)$ & $t$ & $P$ & $95 \% \mathrm{Cl}(\mathrm{B})$ \\
\hline SIC & $0.01(0.09)$ & 0.10 & .92 & {$[-0.17,0.19]$} \\
Victim sex & $0.58(0.20)$ & 2.87 & .005 & {$[0.18,0.97]$} \\
SIC $\times$ Victim sex & $-0.14(0.18)$ & -0.79 & .43 & {$[-0.50,0.22]$} \\
QCAE $^{\mathrm{a}}$ & $-0.01(0.01)$ & -1.09 & .28 & {$[-0.03,0.01]$} \\
ICUa $^{\text {Victimization }}$ & $0.02(0.01)$ & 1.52 & .13 & {$[-0.01,0.05]$} \\
\hline
\end{tabular}

Note. Victim sex ( $\mathrm{I}=$ males, 2 = females $)$. $\mathrm{Cl}=$ confidence interval; SIC $=$ Scale of Intrasexual Competition; QCAE = Questionnaire of Cognitive and Affective Empathy; ICU = Inventory of CallousUnemotional Traits.

${ }^{\mathrm{a} C}$ Covariates.

competition was positively associated with more lenient judgments of revenge pornography and negatively associated with empathy in the whole sample. Moreover, intrasexual competition was positively associated with CU traits in the whole sample, as well as in males and females individually. Correlations observed in the whole sample, as well as for male participants specifically, suggested that more lenient judgments of revenge pornography were reported when the victim was female, relative to male. Furthermore, more lenient judgments of revenge pornography were associated with lower empathy in the whole sample and female subsample. More lenient judgments of revenge pornography were also positively associated with CU traits in the whole sample and male subsample. Empathy was negatively associated with CU in the whole sample and male and female subsamples.

Moderation analyses. We conducted two moderation analyses using Model 1 of the PROCESS plugin for SPSS (Hayes, 2018). In each analysis, intrasexual competition was the focal predictor $(X)$ and judgments of revenge pornography was the dependent variable $(Y)$. The moderator variable was the sex of the victim $(W)$. The variables of $\mathrm{CU}$ traits, empathy, and self-reported victimization were controlled for as covariates. Model coefficients are presented in Tables 3 and 4. Moderated regression trends are presented in Figure 1.

Model I: Male responders. The moderation model for male responders accounted for $13.8 \%$ of the variance in judgments of revenge pornography, and was statistically significant, $F(6,113)=3.01, p=.010$. As indicated in Table 3 , more lenient judgments of revenge pornography were reported when the victim was male. There was no main effect of intrasexual competition, or a significant interaction between intrasexual competition and victim sex, indicating a lack of moderation. No covariates were statistically significant.

Model 2: Female responders. The moderation model for female responders accounted for $21.8 \%$ of the variance in judgments of revenge pornography, and was statistically significant, $F(6,114)=5.29, p<.001$. As indicated in Table 4 , and similar to male 
Table 4. Moderation Coefficients for Female Responders (Study I).

\begin{tabular}{lcccc}
\hline Variable & $B(S E)$ & $t$ & $p$ & $95 \% \mathrm{Cl}(B)$ \\
\hline SIC & $0.03(0.10)$ & 0.24 & .81 & {$[-0.18,0.23]$} \\
Victim sex & $0.41(0.19)$ & 2.15 & .03 & {$[0.03,0.79]$} \\
SIC $\times$ Victim sex & $0.38(0.21)$ & 1.85 & .07 & {$[-0.03,0.79]$} \\
QCAE $^{\mathrm{a}}$ & $-0.02(0.01)$ & -2.44 & .02 & {$[-0.05,-0.00]$} \\
ICUa $^{\text {Victimization }}$ & $0.03(0.01)$ & 2.14 & .03 & {$[0.002,0.05]$} \\
\hline
\end{tabular}

Note. Victim sex (I = males, 2 = females). SIC = Scale of Intrasexual Competition; QCAE $=$ Questionnaire of Cognitive and Affective Empathy; ICU = Inventory of Callous-Unemotional Traits. ${ }^{\mathrm{a} C}$ Covariates.

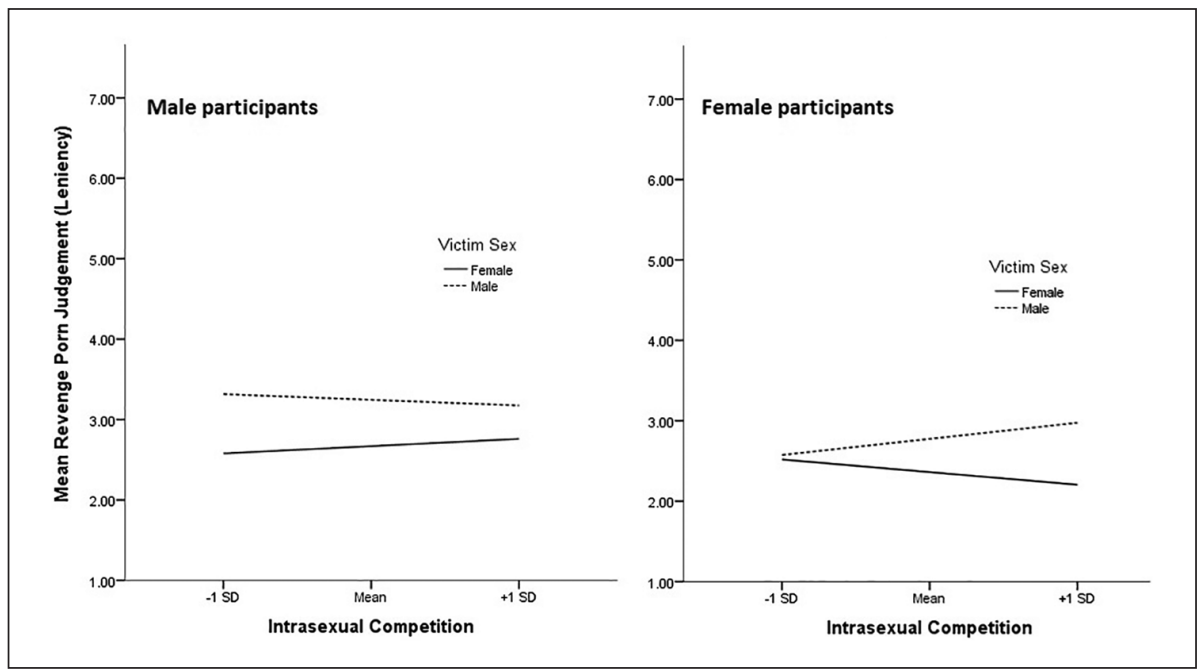

Figure I. Effects of intrasexual competition on judgments of revenge pornography offenses (Study I).

responders, when the victim was male, females reported more lenient judgments of revenge pornography use. Furthermore, although intrasexual competition was not a significant predictor of revenge pornography judgment (see Table 4), there was a trend toward there being a significant interaction between intrasexual competition and victim sex, with females scoring high in intrasexual competition reporting more leniency when the victim was male. In terms of covariates, higher levels of CU traits and lower levels of empathy were associated with more lenient judgments of revenge pornography.

\section{Study 2}

Building on Study 1, this study sought to both replicate our initial findings in a second, independent sample, as well as explore these associations further by manipulating the 
physical attractiveness of victims of revenge pornography offending. We chose to manipulate physical attractiveness as this is a variable that is clearly displayed in the sexually explicit images that is also linked to both intrasexual competition and rival derogation, and potentially to offense-related cognition (e.g., rape myths related to female appearance; Burt, 1980). Although we might expect these effects to be more pronounced among women (Buss \& Dedden, 1990), recent research has suggested that men's use of steroids (a potential route to muscular enhancement) is also associated with intrasexual competition (Harris et al., 2019).

\section{Method}

Participants. To determine our target sample size, we conducted an a priori power analysis using $G^{*}$ Power (version 3.1.9.2). Assuming an anticipated effect size consistent with Study 1 and a standard alpha level of .05, a minimum of 172 participants would be required to have $95 \%$ power in our planned analyses. We aimed to recruit upward of 400 participants to ensure higher levels of statistical power. A total of 402 U.K. participants $\left(M_{\text {age }}=34.91\right.$ years, $S D=11.65$ years; $49.5 \%$ male $)$ completed the online questionnaire advertised through the crowdsourcing website Prolific. Inclusion criteria suggested that participants should be fluent in English, aged 18 years or over, and heterosexual. Using Prolific user-specific identification codes, we were able to automatically exclude respondents of Study 1 from taking part in Study 2, thus avoiding potential biases created by priming or repeating the experiment. Participants provided written informed consent in accordance with approved central university research protocols and national ethical guidelines by ticking a box on both the first and last pages of our online survey. All completers were reimbursed with $£ 0.60$ for their participation.

\section{Materials}

Materials were the same as those outlined in Study 1, save for the inclusion of an extra manipulation of attractiveness. Reliability coefficients for this sample were as follows: SIC (Cronbach's $\alpha=.90)$, JRP (Cronbach's $\alpha=.79$ ), ICU (Cronbach's $\alpha=.82$ ), and QCAE (Cronbach's $\alpha=.88$ ).

Attractiveness manipulation. This study made use of four images that were presented alongside police reports about an alleged revenge pornography offense. These four images represented two males (one attractive, one unattractive) and two females (one attractive, one unattractive). These images were taken from the picture set used by Thomas and Stewart-Williams (2018) and were, in turn, taken from the online site HotOrNot.com. We matched the attractive and unattractive images within each sex as closely as possible with reference to age and general appearance, and used Thomas and Stewart-Williams' (2018) participant ratings to classify them into attractivenesslevel categories. However, we also asked our own participants to rate the attractiveness of each image using a 1 (very unattractive) to 10 (very attractive) scale. Our own participants judged each attractive image as more attractive than the unattractive 


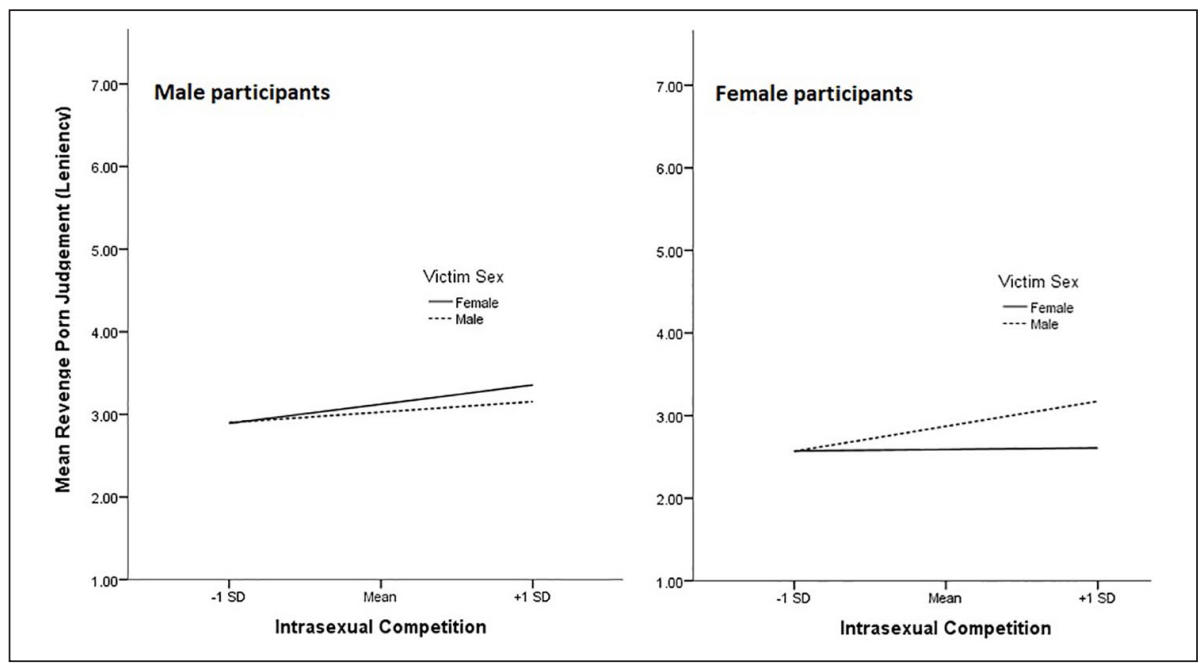

Figure 2. Effects of intrasexual competition on judgments of revenge pornography offenses (Study 2).

image of the same sex, male: $M_{\text {diff }}=2.88, t(401)=26.35, p<.001,95 \% \mathrm{CI}=[2.66$, 3.09]; female: $M_{\text {diff }}=3.11, t(401)=30.01, p<.001,95 \% \mathrm{CI}=[2.90,3.31]$.

\section{Procedure}

The procedure for this study mirrored that of Study 1 and took less than 10 min to complete on average.

\section{Analysis Plan}

In instances of missing data $(N=7)$, the sample mean was calculated. Assumptions were assessed (see Supplemental Material for more information). Pearson correlations were computed between the focal predictor (intrasexual competition), the dependent variable (judgments of revenge pornography), the moderator variables (sex of the victim, victim attractiveness), and covariates (CU traits, empathy, self-reported victimization) in relation to the whole sample, as well as within each sex. We then used Model 3 of the PROCESS plugin for SPSS (version 3; Hayes, 2018) to run two moderated moderation models (one each for male and female responders) on mean-centered data. Moderated regression trends are presented in Figures 2 to 4.

\section{Results}

Sex differences. Means and standard deviations for questionnaire data are reported in Table 5. Independent $t$ tests were used to delineate sex differences within our sample. 


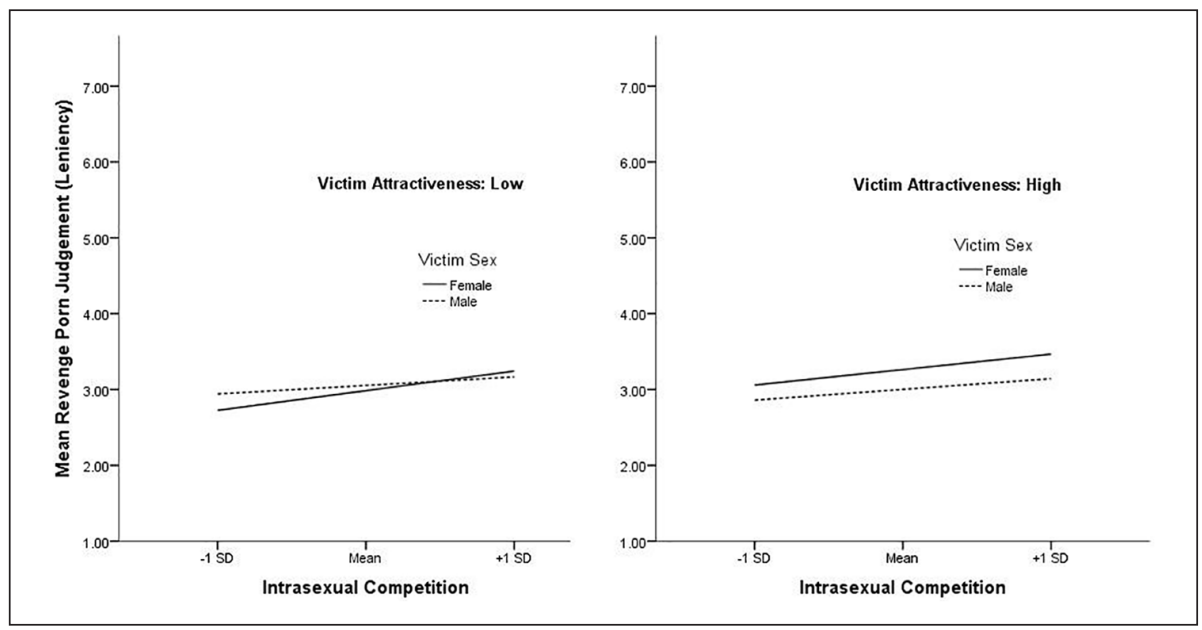

Figure 3. Effects of intrasexual competition on judgments of revenge pornography offenses made by male participants, by victim attractiveness.

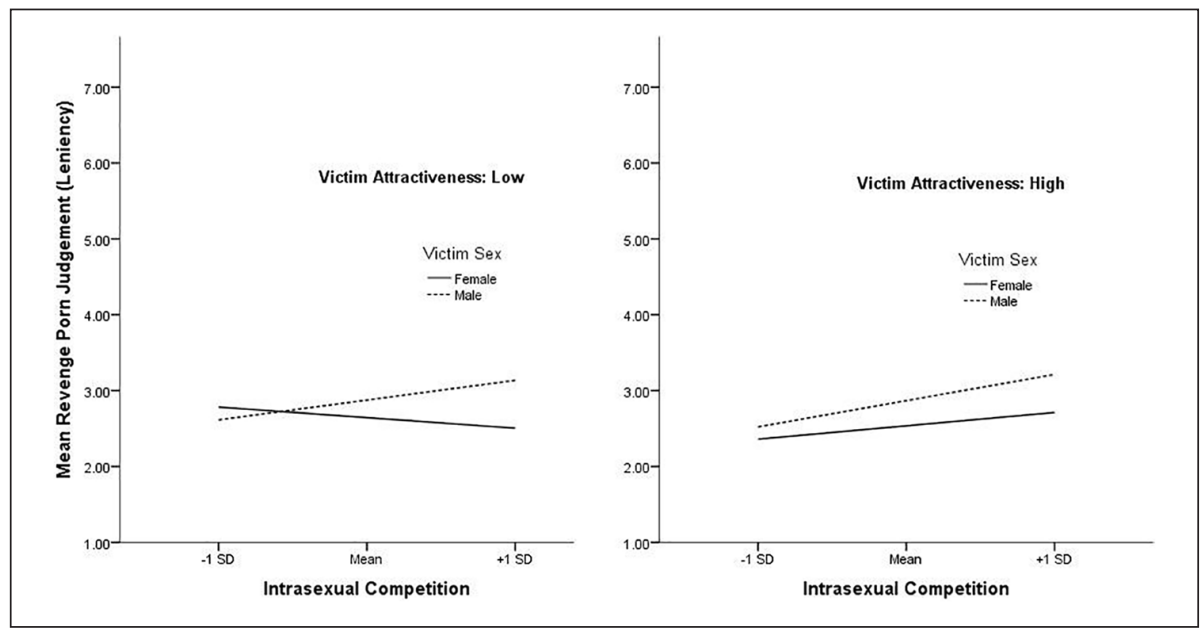

Figure 4. Effects of intrasexual competition on judgments of revenge pornography offenses made by female participants, by victim attractiveness.

Males reported greater levels of intrasexual competition, $t(400)=2.73, p=.006, d=$ 0.27 , and CU traits, $t(400)=5.16, p<.001, d=0.52$, than females, and also reported lower levels of empathy, $t(400)=-4.23, p<.001, d=-0.42$, more lenient judgments to the perpetrators of revenge pornography offenses, $t(400)=3.44, p=.001, d=$ 0.34 , and less incidence of being a victim of revenge pornography, $t(400)=-2.87$, 
Table 5. Descriptive Statistics for Male and Female Questionnaire Scores (Study 2).

\begin{tabular}{lcccr}
\hline Variable & Total & Males & Females & \\
& $M(S D)$ & $M(S D)$ & $M(S D)$ & $p$ \\
\hline Age & $34.91(11.65)$ & $34.38(12.14)$ & $35.44(11.25)$ & .365 \\
SIC & $2.57(1.08)$ & $2.72(1.06)$ & $2.42(1.09)$ & $<.001$ \\
Revenge Pornography Judgments & $2.90(1.04)$ & $3.08(1.02)$ & $2.73(1.04)$ & .001 \\
QCAE & $88.65(10.86)$ & $86.38(11.26)$ & $90.87(9.99)$ & $<.001$ \\
ICU & $33.30(8.19)$ & $35.37(7.80)$ & $31.28(8.08)$ & $<.001$ \\
Victimization & $4.5 \%$ & $1.5 \%$ & $7.4 \%$ & .006
\end{tabular}

Note. Victimization scored by I = yes, $2=$ no. SIC $=$ Scale of Intrasexual Competition, QCAE $=$ Questionnaire of Cognitive and Affective Empathy, ICU = Inventory of Callous-Unemotional Traits.

$p=.006, d=-0.24$. There were no significant differences in age, $t(400)=-0.91$, $p=.365, d=-0.09$, between males and females.

Correlation analysis. We computed bivariate Pearson correlations between predictor, dependent, and moderator variables, as well as covariates (see Table 6). Intrasexual competition was positively associated with more lenient judgments of revenge pornography and CU traits in the whole sample, as well as males and females independently. Furthermore, intrasexual competition was negatively associated with empathy in the whole sample and the female subsample. More lenient judgments of revenge pornography were associated with lower empathy in the whole sample and female subsample, and were also associated with higher levels of CU traits in the whole sample as well as males and females independently. Empathy was negatively associated with $\mathrm{CU}$ in the whole sample and male and female subsamples.

Moderation analyses. Two moderated moderation analyses were conducted. Each analysis mirrored those described in Study 1, save for the implementation of perceived attractiveness of the victim $(Z)$ as a second moderator variable. Again, the variables of CU traits, empathy, and self-reported victimization were controlled for. Model coefficients are presented in Tables 7 and 8 .

Model I: Male responders. The moderated moderation model for male responders accounted for $8.6 \%$ of the variance in judgments of revenge pornography. As indicated in Table 7, although intrasexual competition was positively associated with lenient judgments, the overall model was not statistically significant, $F(10,188)=1.77, p=$ .068 . There were no statistically significant interactions between intrasexual competition, victim sex, perceived victim attractiveness, or judgments of revenge pornography. No covariates were statistically significant.

Model 2: Female responders. The moderated moderation model for female responders accounted for $11.2 \%$ of the variance in judgments of revenge pornography, and 


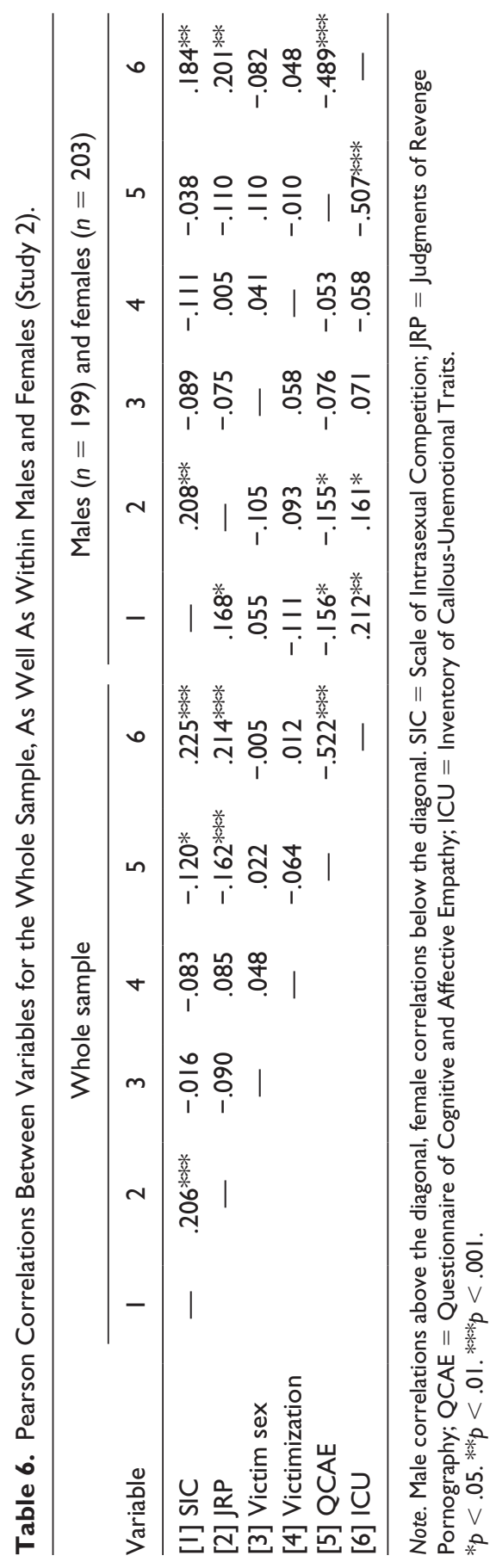


Table 7. Moderated Moderation Coefficients for Male Responders Model.

\begin{tabular}{lcrcc}
\hline Variable & $B(S E)$ & $t$ & $p$ & $95 \% \mathrm{Cl}(B)$ \\
\hline SIC & $0.17(0.07)$ & 2.32 & .02 & {$[0.03,0.3 \mathrm{II}]$} \\
Victim sex & $0.09(0.14)$ & 0.65 & .52 & {$[-0.19,0.38]$} \\
Attractiveness & $0.11(0.14)$ & 0.80 & .43 & {$[-0.17,0.40]$} \\
SIC $\times$ Victim sex & $0.10(0.14)$ & 0.70 & .49 & {$[-0.18,0.38]$} \\
SIC $\times$ Attractiveness & $-0.01(0.15)$ & -0.09 & .93 & {$[-0.30,0.27]$} \\
Victim sex $\times$ Attractiveness & $0.33(0.29)$ & 1.16 & .25 & {$[-0.23,0.90]$} \\
SIC $\times$ Victim sex $\times$ Attractiveness & $-0.08(0.29)$ & -0.28 & .78 & {$[-0.64,0.49]$} \\
QCAEa & $-0.00(0.01)$ & -0.18 & .86 & {$[-0.02,0.0 I]$} \\
ICUa $^{\text {Victimization }}{ }^{a}$ & $0.02(0.01)$ & 1.93 & .06 & {$[-0.001,0.04]$} \\
\hline
\end{tabular}

Note. Victim sex $(I=$ males, 2 = females $)$. Cl = confidence interval; SIC = Scale of Intrasexual Competition; QCAE = Questionnaire of Cognitive and Affective Empathy; ICU = Inventory of CallousUnemotional Traits.

${ }^{\mathrm{a} C}$ Covariates.

Table 8. Moderated Moderation Coefficients for Female Responders Model.

\begin{tabular}{lrrrc}
\hline Variable & \multicolumn{1}{c}{$B(S E)$} & \multicolumn{1}{c}{$t$} & $p$ & $95 \% \mathrm{Cl}(B)$ \\
\hline SIC & $0.15(0.07)$ & 2.19 & .03 & {$[0.01,0.28]$} \\
Victim sex & $0.28(0.14)$ & 1.98 & .05 & {$[0.001,0.56]$} \\
Attractiveness & $-0.06(0.14)$ & -0.41 & .68 & {$[-0.34,0.22]$} \\
SIC $\times$ Victim sex & $0.26(0.13)$ & 1.97 & .05 & {$[0.001,0.52]$} \\
SIC $\times$ Attractiveness & $0.18(0.13)$ & 1.40 & .16 & {$[-0.08,0.44]$} \\
Victim sex $\times$ Attractiveness & $0.10(0.28)$ & 0.35 & .73 & {$[-0.46,0.66]$} \\
SIC $\times$ Victim sex $\times$ Attractiveness & $-0.21(0.26)$ & -0.80 & .42 & {$[-0.73,0.31]$} \\
QCAEa & $-0.01(0.01)$ & -0.88 & .38 & {$[-0.02,0.01]$} \\
ICUa $_{\text {Victimization }}{ }^{\mathrm{a}}$ & $0.01(0.01)$ & 1.40 & .16 & {$[-0.01,0.04]$} \\
\hline
\end{tabular}

Note. Victim sex $(\mathrm{I}=$ males, $2=$ females $)$. $\mathrm{Cl}=$ confidence interval; SIC = Scale of Intrasexual Competition, QCAE = Questionnaire of Cognitive and Affective Empathy, ICU = Inventory of CallousUnemotional Traits.

${ }^{\mathrm{a} C}$ Covariates.

was statistically significant, $F(10,192)=2.43, p=.010$. As indicated in Table 8 , an increase in intrasexual competition was positively associated with lenient judgments. Similarly, when the victim was male, this was associated with more lenient judgments. Furthermore, there was a significant interaction between intrasexual competition and victim sex, such that females who scored high in intrasexual competition showed more lenient judgments when the victim was male. There were neither significant interactions between victim attractiveness and intrasexual competition or victim sex, nor a significant three-way interaction, indicating a lack of moderation of the association 
between intrasexual competition and revenge pornography judgments by perceived attractiveness of the victim. No covariates were statistically significant.

\section{General Discussion}

\section{Overview of Key Findings}

Throughout the two independently sampled studies, we report a positive association between intrasexual competition and more lenient judgments of revenge pornography. However, when sex was considered as a moderator of this association, we observed the unexpected trend of higher levels of intrasexual competition being associated with more lenient judgments made by female participants about revenge pornography offenses involving male, but not female, victims. This directly opposes our hypothesis that higher levels of intrasexual competition would predict more lenient judgments of revenge pornography offenses involving same-sex victims, either generally (Study 1) or when levels of attractiveness were manipulated (Study 2).

The concept of intrasexual competition has roots in evolutionary biology, and, in the context of revenge pornography, may manifest in an increased likelihood to share (or endorse the sharing of) sexually explicit images of another. On average, positive associations between intrasexual competition and more lenient judgments of revenge pornography observed for men and women in these studies add weight to this claim, with this mechanism likened to the mating strategies of competitor derogation and manipulation highlighted in Fisher and Cox (2011). Moreover, we anticipated higher reports of intrasexual competition to associate with harsher views of same-sex victims (and so, more lenient views of the offense itself) as a function of the distribution of the victim's most intimate images reducing their value as a rival mate (Buss et al., 2017). As such, it is surprising to find that women reported more lenient judgments of revenge pornography offenses involving male, not female victims in the current study, and that no interaction with attractiveness (indicative of a social threat) was found.

Secondary findings (correlations) of these investigations suggest associations between more lenient judgments of revenge pornography offenses and both higher levels of CU traits and lower levels of empathy. CU traits were also negatively associated with empathy (see also Hodsoll et al., 2014). Such results go some way to support previous findings of associations between CU-related traits and/or empathy and variation in the frequency of, and willingness to engage in, cyber-related deviancy, and the nonconsensual dissemination of intimate text messages (Clancy et al., 2019; Doane et al., 2014; Goodboy \& Martin, 2015; March et al., 2017; Steffgen et al., 2011; Wright et al., 2018). Moreover, psychopathic traits more specifically have been associated with an increased likelihood to engage in acts of revenge following the breakdown of a relationship (Rasmussen \& Boon, 2014). As such, the findings of the current study support the view that a reduced ability to resonate with (or a callous disregard for) the feelings and emotions of the victims are associated with more lenient judgments of revenge pornography offenses. 


\section{Interpretation of Findings}

In this section, we offer potential explanations as to why (a) the significant bivariate correlations between intrasexual competition and more lenient judgments of revenge pornography were not observed within the moderation models and (b) the unexpected trends of higher intrasexually competitive women reporting more lenient judgments for male, but not female, victims. The most parsimonious explanation for this first point is that the addition of the covariates (CU traits, empathy, and victimization) may account for a substantial proportion of the variance explained within the relationship between intrasexual competition and revenge pornography judgments. This explanation is partially supported by CU traits and empathy being significant in the second moderation model (female respondents) reported in Study 1; however, these covariates do not reach statistical significance in any other model reported.

A second explanation could be that the measure of intrasexual competition (the SIC; Buunk \& Fisher, 2009) may share variance with other unobserved constructs. That is, we did not see the expected effects of higher levels of intrasexual competition predicting more lenient judgments of revenge pornography offenses involving samesex victims, either generally (Study 1) or when we manipulated attractiveness levels (Study 2). Instead, we observed the unexpected trend of higher intrasexual competition levels being associated with more lenient judgments made by female participants about offenses with male victims. This is at odds with established thinking about sexual victimization, and particularly about the alleged societal acceptance of revenge pornography. That is, feminist writers commonly refer to sexual offending (and lenient judgments thereof) as being motivated by the patriarchal desire of men to be socially dominant over women (Brownmiller, 1975; for a review of this argument specifically in relation to revenge pornography, see McGlynn et al., 2017). Some readers may interpret our findings as being reflective of intrasexual competition among women leading to victim blaming of males. We do not think that this would be appropriate, and this would not necessarily be in line with established theories of wider sexual offending, such as contact offenses or viewing child pornography (e.g., Finkelhor, 1984; Seto, 2019; Ward \& Siegert, 2002). Although not specific to revenge pornography, these models cite sexual arousal (or a desire for sexual gratification) as a key motivating factor for sexual offending. We see intrasexual competition among females as reflective of this, possibly due to its co-occurrence with sexual promiscuity or a sociosexual orientation that is inclined toward short-term mating (Buunk \& Fisher, 2009). Applying these relationships directly to our data, we may see female participants scoring high on the SIC being more lenient about cases involving male victims due to an increased desire to have potential access to their sexualized images. However, this explanation has two key limitations. First, if this were the case, we would expect to see comparable results for males. Second, promiscuity and sociosexual orientation were only weakly correlated with intrasexual competition in Buunk and Fisher (2009). Of interest, and subsequent to our data collection, a recent alternative to the SIC - the Intrasexual Rivalry Scale — has been proposed (Karimi-Malekabadi et al., 2019). This scale reports a two-factor structure of intrasexual competition (self-promotion and 
rival derogation), and aids to overcome perceived limitations of the SIC through systematically developing items that are valid across both Western and non-Western countries.

In contrast, recent research has linked intrasexual competition among women with an increased propensity to take sexually explicit images of themselves (Blake et al., 2018). That is, using population data, it was reported how posting rates of self-produced sexual images were not associated with city- or county-level indices of gender inequality, but rather were related to income inequality. Specifically, Blake et al. (2018) suggest a disproportionate share of the wealth in favor of males incentivize women to sexualize themselves as a means of competing with their rivals to attract high-income men. Applying this to the present work, we might hypothesize that those females scoring higher on intrasexual competition in our sample may also have a higher propensity to take, post, or share sexual "selfies." If this is the case, then it becomes feasible that lower leniency (or more punitive) judgments made by these participants for cases involving female victims in Study 1 might stem from an affinity with those victims.

A final possible explanation is based around the assumption that women who are higher in intrasexual competition (and as such are higher in sociosexuality and shortterm mating tendencies) will more frequently interact with men pursuing similar strategies. Such men are more likely to be directly aggressive (Cross, 2010) and sexually coercive (Westerlund et al., 2010), and express greater rape myth acceptance (Yost \& Zurbriggen, 2006). As such, these women may be harsher toward male victims so that they are less likely to encounter these men in a dating context, whereby they are at greater risk of sexual violence than men (Bullock \& Beckson, 2011). This explanation helps to account for the sex differences observed in this investigation. ${ }^{1}$

Of interest, is a discrepancy between the absence of direct effects between intrasexual competition and judgments of revenge pornography (as a function of sex) in Study 1, and prominent effects being observed in Study 2. This disparity is neither fully explained by a larger sample size in the second study, nor by said effects being masked by the interaction with victim sex (as this does not explain the finding in males, where the interaction was not significant). The only other methodological alteration between the two studies, and so a likely target for future investigation, is the use of images to accompany the vignette and/or the framing of these vignettes in the style of a police report. It is possible that this method, used to operationalize our research design, helped to elicit this novel finding, possibly as a mechanism of increasing the perceived validity of the task.

\section{Limitations and Future Direction}

First, although the findings of this investigation were replicated across two, independent samples, both samples were derived from the United Kingdom. Although this research is contextualized within wider recent legislation developments pertaining to revenge pornography across the Western world and so likely has international impact, the authors acknowledge cross-cultural variation in values and social norms, and so, there is likely 
value in international replication of these findings. Second, interpretation of our findings suggests a currently unmeasured overlap between intrasexual competition and other personality traits (e.g., sexual promiscuity). Moreover, across both studies, our models were only able to explain between $8.6 \%$ and $21.8 \%$ of the observed variance, suggesting that there are several unexamined factors that need to be identified. As such, future investigation should seek to explore additional personality traits using a similar methodological approach to that reported here. Third, the vignettes used throughout this investigation implied that the act of revenge pornography was facilitated by infidelity in the relationship. It is possible that this might have played some role in the responses of participants who have cheated, or have been cheated on in the past. Future investigations using this method should seek to control for this variation. Fourth, in the context of existing research suggesting that both intrasexual competition (Massar et al., 2012) and receiving sexual images (Garcia et al., 2016) is most prevalent in younger adults, it is possible that the samples reported here may respond differently from other age groups. As such, this area of research is an ideal candidate for future replications. Fifth, the measure of revenge pornography judgments used in the present study (Bothamley \& Tully, 2018) is unvalidated in terms of its factor structure. However, the limited number of items used in its original development leads us to the conclusion that a more systematic approach to developing such a measure is warranted to capture the range of judgments that people could make in relation to this type of offending behavior. Future investigations may thus use large pools of potential items to develop a rigorous and comprehensive measure of judgments about revenge pornography offending and victimization. Finally, and in fitting with the movement to recognize the use of revenge pornography as just one point in the continuum of image-based sexual abuse (McGlynn et al., 2017), it is essential to extend these findings to judgments of other related offenses such as upskirting, the production of deep-fake pornography, and cyber flashing. Upskirting involves taking images of the pubic area of another underneath their outer clothing, deep-fake pornography involves digitally manipulating an individual's image in a sexualized manner, and cyber flashing uses Bluetooth technology to send sexually inappropriate images to nonconsenting strangers. By undertaking replication and extension studies such as these, it may be possible to examine whether the effects observed in the present study are limited to "revenge pornography" offending, or whether they apply across McGlynn et al.'s (2017) hypothesized continuum of image-based sexual abuse.

\section{Authors' Note}

The authors take responsibility for the integrity of the data, the accuracy of the data analyses, and have made every effort to avoid inflating statistically significant results. Open data and a preprint of this article are available at https://osf.io/y29fq/?view_only=568a2c403fcf42828091 $4 \mathrm{c} 149063 \mathrm{db} 95$.

\section{Declaration of Conflicting Interests}

The author(s) declared no potential conflicts of interest with respect to the research, authorship, and/or publication of this article. 


\section{Funding}

The author(s) disclosed receipt of the following financial support for the research, authorship, and/or publication of this article: This work was supported by an Undergraduate Research Scholarship Scheme (URSS) fund (£200) from University of Derby and a Scholarship Project for Undergraduate Research (SPUR) fund (£300) from Nottingham Trent University.

\section{ORCID iDs}

Dean Fido (iD https://orcid.org/0000-0001-8454-3042

Craig A. Harper (iD) https://orcid.org/0000-0002-3172-0129

\section{Supplemental Material}

Supplemental material for this article is available at https://osf.io/y29fq/?view_only $=568 \mathrm{a} 2 \mathrm{c} 40$ $3 \mathrm{fcf} 428280914 \mathrm{c} 149063 \mathrm{db} 95$.

\section{Note}

1. The authors would like to thank an anonymous reviewer for suggesting this likely explanation.

\section{References}

Arnocky, S., \& Vaillancourt, T. (2017). Sexual competition among women: A review of the theory and supporting evidence. In M. L. Fisher (Ed.), The Oxford handbook of women and competition (pp. 25-39). Oxford University Press. https://doi.org/10.1093/ oxfordhb/9780199376377.013.3

Baguley, T. (2012). Serious stats: A guide to advanced statistics for the behavioral sciences. Palgrave Macmillan.

Bates, S. (2017). Revenge porn and mental health: A qualitative analysis of the mental health effects of revenge porn on female survivors. Feminist Criminology, 12, 22-42. https://doi. org/10.1177/1557085116654565

Blake, K. R., Bastian, B., Denson, T. F., Grosjean, P., \& Brooks, R. C. (2018). Income inequality not gender inequality positively covaries with female sexualisation on social media. Proceedings of the National Academy of Sciences of the United States of America, 115, 8722-8727. https://doi.org/10.1073/pnas.1717959115

Bloom, S. (2014). No vengeance for revenge porn victims: Unravelling why this latest femalecentric, intimate-partner offense is still legal, and why we should criminalize it. Fordham Urban Law Journal, 42, 233-289.

Bothamley, S., \& Tully, R. J. (2018). Understanding revenge pornography: Public perceptions of revenge pornography and victim blaming. Journal of Aggression, Conflict and Peace Research, 10, 1-10. https://doi.org/10.1108/JACPR-09-2016-0253

Brewer, G., Hunt, D., James, G., \& Abell, L. (2015). Dark triad traits, infidelity and romantic revenge. Personality and Individual Differences, 83, 122-127. https://doi.org/10.1016/j. paid.2015.04.007

Brownmiller, S. (1975). Against our will: Men, women and rape. Simon \& Schuster.

Bullock, C. M., \& Beckson, M. (2011). Male victims of sexual assault: Phenomenology, psychology, physiology. Journal of the American Academy of Psychiatry and the Law, 39, 197-205. 
Burt, M. R. (1980). Cultural myths and support for rape. Journal of Personality and Social Psychology, 38, 217-230. https://doi.org/10.1037/0022-3514.38.2.217

Buss, D. M., \& Dedden, L. A. (1990). Derogation of competitors. Journal of Social and Personal Relationships, 7, 395-422. https://doi.org/10.1177/0265407590073006

Buss, D. M., Goetz, C., Duntley, J. D., Asao, K., \& Conroy-Beam, D. (2017). The mate switching hypothesis. Personality and Individual Differences, 104, 143-149. https://doi. org/10.1016/j.paid.2016.07.022

Buunk, A. P., \& Fisher, M. (2009). Individual differences in intrasexual competition. Journal of Evolutionary Psychology, 7, 37-48. https://doi.org/10.1556/JEP.7.2009.1.5

Campbell, A. (2004). Female competition: Causes, constraints, content, and contexts. Journal of Sex Research, 41, 16-26. https://doi.org/10.1080/00224490409552210

Citron, D. K., \& Franks, M. A. (2014). Criminalizing revenge porn. Wake Forest Law Review, 49, 345-391.

Clancy, E. M., Klettke, B., \& Halford, D. J. (2019). The dark side of sexting-Factors predicting the dissemination of sexts. Computers in Human Behavior, 92, 266-272. https://doi. org/10.1016/j.chb.2018.11.023

Cross, C. P. (2010). Sex differences in same-sex direct aggression and sociosexuality: The role of risky impulsivity. Evolutionary Psychology, 8, 4779-4792. https://doi. org $/ 10.1177 / 147470491000800418$

Darwin, C. (1871). The descent of man and selection in relation to sex. Murray.

Davies, S. E. (2017). "It's her fault for sending them in the first place" vs "Blame would definitely be with the person who released them": A study to explore whether the opinions of males and females differ in regards to revenge porn, and if the level of male hypermasculinity has any effect [Unpublished doctoral dissertation]. Cardiff Metropolitan University.

Davis, A. C., Dufort, C., Desrochers, J., Vaillancourt, T., \& Arnocky, S. (2018). Gossip as an intrasexual competition strategy: Sex differences in gossip frequency, content, and attitudes. Evolutionary Psychological Science, 4, 141-153. https://doi.org/10.1007/s40806017-0124-6

Dawkins, J. T. (2015). A dish served cold: The case for criminalizing revenge pornography. Cumberland Law Review, 45, 395-447.

Decety, J., \& Lamm, C. (2009). Empathy versus personal distress-Recent evidence from social neuroscience. In J. Decety \& W. Ickes (Eds.), The social neuroscience of empathy (pp. 199-213). The MIT Press.

Doane, A. N., Pearson, M. R., \& Kelly, M. L. (2014). Predictors of cyberbullying perpetration among college students: An application of the theory of reasoned action. Computers in Human Behavior, 36, 154-162. https://doi.org/10.1016/j.chb.2014.03.051

Fay, M. (2018). The naked truth: Insufficient coverage for revenge porn victims at State law and the proposed Federal legislation to adequately redress them. Boston College Law Review, 59, 1839-1871.

Fern, A. (2014). 23 reasons why you should never, ever take a nude pic again. Elite Daily. https://www.elitedaily.com/women/taking-a-selfie-pic-nudie/737323

Finkelhor, D. (1984). Child sexual abuse: New theory and research. The Free Press.

Fisher, M., \& Cox, A. (2011). Four strategies used during intrasexual competition for mates. Personal Relationships, 18, 20-38. https://doi.org/10.1111/j.1475-6811.2010.01307.x

Frick, P. J. (2004). Inventory of callous-unemotional traits [Unpublished rating scale]. University of New Orleans. 
Garcia, J. R., Gesselman, A. N., Siliman, S. A., Perry, B. L., Coe, K., \& Fisher, H. E. (2016). Sexting among singles in the USA: Prevalence of sending, receiving, and sharing sexual messages and images. Sexual Health, 13, 428-435.

Giammarco, E. A., \& Vernon, P. A. (2014). Vengeance and the dark triad: The role of empathy and perspective taking in trait forgiveness. Personality and Individual Differences, 67, 23-29. https://doi.org/10.1016/j.paid.2014.02.010

Goodboy, A. K., \& Martin, M. M. (2015). The personality profile of a cyberbully: Examining the dark triad. Computers in Human Behavior, 49, 1-4. https://doi.org/10.1016/j. chb.2015.02.052

Hadwin, J. (2017). Victim blaming and third-person effect: A comparative analysis of attitudes for revenge porn and sexual assault [Unpublished Master's dissertation]. Oklahoma State University.

Harris, M., Dunn, M., \& Alwyn, T. (2019). Intrasexual competition as a potential influence on anabolic-androgenic steroid use initiation. Journal of Health Psychology, 24, 1210-1220. https://doi.org/10.1177/1359105317692145

Hayes, A. F. (2018). Introduction to mediation, moderation, and conditional process analysis (2nd ed.). Guilford Press.

Henry, N., \& Powell, A. (2014). Preventing sexual violence: Interdisciplinary approaches to overcoming a rape culture. Palgrave Macmillan.

Henry, N., \& Powell, A. (2016). Sexual violence in the digital age: The scope and limits of criminal law. Social \& Legal Studies, 25, 397-418. https://doi.org/10.1177/0964663915624273

Ho, R., ForsterLee, L., ForsterLee, R., \& Crofts, N. (2002). Justice versus vengeance: Motives underlying punitive judgements. Personality and Individual Differences, 33, 365-377. https://doi.org/10.1016/S0191-8869(01)00161-1

Hodsoll, S., Lavie, N., \& Viding, E. (2014). Emotional attentional capture in children with conduct problems: The role of callous-unemotional traits. Frontiers in Human Neuroscience, 8, Article 570. https://doi.org/10.3389/fnhum.2014.00570

Karimi-Malekabadi, F., Ghanbarian, E., Afhami, R., \& Chegeni, R. (2019). Theory-driven assessment of intrasexual competition. Evolutionary Psychological Science, 5, 286-293. https://doi.org/10.1007/s40806-018-00185-7

Kimonis, E. R., Branch, J., Hagman, B., Graham, N., \& Miller, C. (2013). The psychometric properties of the Inventory of Callous-Unemotional Traits in an undergraduate sample. Psychological Assessment, 25, 84-93. https://doi.org/10.1037/a0029024

Knapen, J. E. P., Blaker, N. M., \& van Vugt, M. (2018). The Napoleon Complex: When shorter men take more. Psychological Science, 29(7), 1134-1144. https://doi. org/10.1177/0956797618772822

Lageson, S. E., McElrath, S., \& Palmer, K. E. (2018). Gendered public support for criminalizing "revenge porn." Feminist Criminology, 14, 560-583. https://doi. org/10.1177/1557085118773398

Lalumière, M. L., Harris, G. T., Quinsey, V. L., \& Rice, M. E. (2005). The causes of rape: Understanding individual differences in male propensity for sexual aggression. American Psychological Association.

March, E., Grieve, R., Marrington, J., \& Jonason, P. K. (2017). Trolling on tinder ${ }^{\circledR}$ (and other dating apps): Examining the role of the Dark Tetrad and impulsivity. Personality and Individual Differences, 110, 139-143. https://doi.org/10.1016/j.paid.2017.01.025 
Massar, K., Buunk, A. P., \& Rempt, S. (2012). Age differences in women's tendency to gossip are mediated by their mate value. Personality and Individual Differences, 52, 106-109. https://doi.org/10.1016/j.paid.2011.09.013

McAndrew, F. T. (2017). How "the gossip" became a woman and how "gossip" became her weapon of choice. In M. L. Fisher (Ed.), The Oxford handbook of women and competition (pp. 191-208). Oxford University Press.

McCaul, K. D., Veltum, L. G., Boyechko, V., \& Crawford, J. J. (1990). Understanding attributions of victim blame for rape: Sex, violence, and foreseeability. Journal of Applied Social Psychology, 20, 1-26. https://doi.org/10.1111/j.1559-1816.1990.tb00375.x

McGlynn, C., Rackley, E., \& Houghton, R. (2017). Beyond "revenge porn": The continuum of image-based sexual abuse. Feminist Legal Studies, 25, 25-46. https://doi.org/10.1007/ s10691-017-9343-2

Muggleton, N. K., Tarran, S. R., \& Fincher, C. L. (2018). Who punishes promiscuous women? Both women and men are prejudiced towards sexually-accessible women, but only women inflict costly punishment. Evolution and Human Behavior, 40, 259-268. https://doi. org/10.1016/j.evolhumbehav.2018.12.003

Niemi, L., \& Young, L. (2016). When and why we see victims as responsible: The impact of ideology on attitudes towards victims. Personality and Social Psychology Bulletin, 42, 1227-1242. https://doi.org/10.1177/0146167216653933

Patella-Rey, P. (2018). Beyond privacy: Bodily integrity as an alternative framework for understanding non-consensual pornography. Information, Communication \& Society, 21, 786-791. https://doi.org/10.1080/1369118X.2018.1428653

Peer, E., Brandimarte, L., Samat, S., \& Acquisti, A. (2017). Beyond the Turk: Alternative platforms for crowdsourcing behavioral research. Journal of Experimental Social Psychology, 70, 153-163. https://doi.org/10.1016/j.jesp.2017.01.006

Puts, D. (2016). Human sexual selection. Current Opinion in Psychology, 7, 28-32. https://doi. org/10.1016/j.copsyc.2015.07.011

Rasmussen, K. R., \& Boon, S. D. (2014). Romantic revenge and the dark triad: A model of impellance and inhibition. Personality and Individual Differences, 56, 51-56. https://doi. org/10.1016/j.paid.2013.08.018

Reniers, R. L. E. P., Corcoran, R., Drake, R., Shryane, N. M., \& Völlm, B. A. (2011). The QCAE: A Questionnaire of Cognitive and Affective Empathy. Journal of Personality Assessment, 93, 84-95. https://doi.org/10.1080/00223891.2010.528484

Reynolds, T., Baumeister, R. F., \& Maner, J. K. (2018). Competitive reputation manipulation: Women strategically transmit social information about romantic rivals. Journal of Experimental Social Psychology, 78, 195-209. https://doi.org/10.1016/j.jesp.2018.03.011

Ringrose, J., \& Renold, E. (2012). Slut-shaming, girl power and "sexualisation": Thinking through the politics of the international SlutWalks with teen girls. Gender and Education, 24, 333-343. https://doi.org/10.1080/09540253.2011.645023

Seto, M. C. (2019). The motivation-facilitation model of sexual offending. Sexual Abuse, 31, 3-24. https://doi.org/10.1177/1079063217720919

Sherlock, P. (2016, April 27). Revenge pornography victims as young as 11, investigation finds. BBC News. https://www.bbc.co.uk/news/uk-england-36054273

Steffgen, G., König, A., Pfetsch, J., \& Melzer, A. (2011). Are cyberbullies less empathic? Adolescents' cyberbullying behavior and empathic responsiveness. Cyberpsychology, Behavior, and Social Networking, 14, 643-648. https://doi.org/10.1089/cyber.2010.0445 
Stroud, S. R. (2014). The dark side of the online self: A pragmatist critique of the growing plague of revenge porn. Journal of Mass Media Ethics, 29, 168-183. https://doi.org/10.10 80/08900523.2014.917976

Thomas, A. G., \& Stewart-Williams, S. (2018). Mating strategy flexibility in the laboratory: Preferences for long- and short-term mating change in response to evolutionary relevant variables. Evolution and Human Behavior, 39, 82-93. https://doi.org/10.1016/j.evolhumbehav.2017.10.004

Thornhill, R., \& Palmer, C. T. (2000). A natural history of rape: Biological bases of sexual coercion. The MIT Press.

Vaillancourt, T. (2013). Do human females use indirect aggression as an intrasexual competition strategy? Philosophical Transactions of the Royal Society B, 368, Article 20130080. https://doi.org/10.1098/rstb.2013.0080

Vaillancourt, T., \& Sharma, A. (2011). Intolerance of sexy peers: Intrasexual competition among women. Aggressive Behavior, 37, 569-577. https://doi.org/10.1002/ab.20413

Walker, K., \& Sleath, E. (2017). A systematic review of the current knowledge regarding revenge pornography and non-consensual sharing of sexually explicit media. Aggression and Violent Behavior, 36, 9-24. https://doi.org/10.1016/j.avb.2017.06.010

Ward, T., \& Siegert, R. J. (2002). Toward a comprehensive theory of child sexual abuse: A theory knitting perspective. Psychology, Crime \& Law, 8, 319-351. https://doi. org/10.1080/10683160208401823

Westerlund, M., Santtila, P., Johansson, A., Varjonen, M., Witting, K., Jern, P., \& Sandnabba, K. N. (2010). Does unrestricted sociosexual behaviour have a shared genetic basis with sexual coercion? Psychology, Crime \& Law, 16(1-2), 5-23. https://doi. org/10.1080/10683160802621925

Wright, M. F., Harper, B. D., \& Wachs, S. (2018). The associations between cyberbullying and callous-unemotional traits among adolescents: The moderating effect of online disinhibition. Personality and Individual Differences, 140, 41-45. https://doi.org/10.1016/j. paid.2018.04.001

Yost, M. R., \& Zurbriggen, E. L. (2006). Gender differences in the enactment of sociosexuality: An examination of implicit social motives, sexual fantasies, coercive sexual attitudes, and aggressive sexual behavior. The Journal of Sex Research, 43(2), 163-173. https://doi. org/10.1080/00224490609552311 